DOI: 10.15690/vsp.v17i4.1921

\title{
О.В. Кожевникова
}

Национальный медицинский исследовательский центр здоровья детей, Москва, Российская Федерация

\section{Комментарий к статье «Роль железа в патогенезе расстройств аутистического спектра у детей"}

\section{Контактная информация:}

Кожевникова Ольга Викторовна, кандидат медицинских наук, врач высшей категории, заведующая отделением инструментальной и лабораторной диагностики КДЦ НМИЦ здоровья детей

Адрес: 119991, Москва, Ломоносовский пр-т, д. 2, стр. 1, тел.: +7 (495) 967-14-20, e-mail: fd@nczd.ru

Статья поступила: 23.08.2018 г., принята к печати: 26.08.2018 г.

(Для цитирования: Кожевникова О.В. Комментарий к статье О.В. Костиной «Роль железа в патогенезе расстройств аутистического спектра у детей”. Вопросы современной педиатрии. 2018; 17 (4): 287-288. doi: 10.15690/ vsp.v17i4.1921)

Расстройство аутистического спектра (РАС) - это нарушение социальных взаимодействий и коммуникаций, сопровождающееся ограниченным и повторяющимся поведением. Понятие РАС в настоящее время представляет собой континуум психологических состояний (классический аутизм, синдром Аспергера, синдром Ретта, неспецифическое первазивное нарушение развития, детское дезинтегративное расстройство), требующих умеренной или существенной поддержки для преодоления дефицита социального общения и ограниченного, повторяющегося поведения (Американская психиатрическая ассоциация, 2013) [1].

Проблемы сна заявлены одним из ключевых факторов при РАC [2]. Характерно уже на ранних сроках заболевания (до 2 лет) появление нарушений электроэнцефалографического паттерна сна и бодрствования, которые рассматриваются как самые ранние симптомы РАС, сохраняющиеся впоследствии у пациента всю его жизнь [3]. В то же время показано, что нарушения сна при РАС весьма разнообразны, что объяснимо широким спектром патологии, включенной в эту группу больных. Проводятся изучения генетических, эпигенетических, психологических и социальных/экологических факторов, участвующих в формировании нарушений сна при РАС для лучшего понимания основных симптомов заболевания. Нарушение сна рассматривается как проявление основного заболевания. Поэтому вызывает сомнение тот факт, что только нормализацией уровня железа в сыворотке крови у детей с РАС можно добиться "коррекции нарушений сна", и не удивительно, что другие исследования не подтвердили эти результаты.
Примером того, какое разнообразие патофизиологических изменений может наблюдаться у детей с РАС, служит и тот факт, что одни и те же фармакопрепараты могут быть эффективны у одних и совершенно бесполезны у других детей. В исследовании на животных было показано, что экспериментальная блокада холинергических рецепторов в структурах мозга, входящих в вентральную систему внимания, вызывала сходные с аутизмом нарушения поведения, проявляющиеся его ригидностью, узким диапазоном интересов и избеганием социальных контактов. Направленное введение ацетилхолина полностью снимало симптомы "аутизма". В свете этих данных была выдвинута гипотеза, требующая, конечно, дальнейшего исследования, что у определенной подгруппы детей с РАС при наличии холинергического дефицита возможна медикаментозная коррекция поведения $[4,5]$. В обзоре О.В. Костиной указана связь между сидеропенией и дефицитом холина - предшественника ацетилхолина [6]. Таким образом, исследования в этом направлении могут помочь выявлению метаболически однородных групп пациентов для создания персонифицированных коррекционных программ. В то же время в представленном обзоре О.В. Костиной показана противоречивость результатов, полученных при изучении обмена железа у детей с РАС, недоказанность его участия в патогенезе РАС.

Обзор О.В. Костиной интересный, показывает высокую значимость железа в процессах формирования структуры и функции центральной нервной системы, развития когнитивных и поведенческих навыков у детей. Показано влияние перинатального дефицита железа на повышение риска развития когнитивных и психи-

Olga V. Kozhevnikova

Natuional Medical Research Center of Children's Health, Moscow, Russian Federation

\section{Commentary on the Article "The Role of Iron in the Pathogenesis of Autism Spectrum Disorders in Children"}

(For citation: Kozhevnikova Olga V. Commentary on the Article "The Role of Iron in the Pathogenesis of Autism Spectrum Disorders in Children". Voprosy sovremennoi pediatrii - Current Pediatrics. 2018; 17 (4): 287-288. doi: 10.15690/vsp.v17i4.1921) 
ческих нарушений у детей и возможного вовлечения железа в патогенез РАС уже на ранних этапах онтогенеза. В то же время заключение к статье, в котором автором поставлена задача поиска "пороговых уровней дефицита железа, являющихся решающим для развития РАС" и выдвинуто предложение искать оптимальные дозы препаратов железа, которые будут "снижать риск развития этого заболевания при их приеме во время беременности", не соответствует изложенному материалу и, по всей видимости, преждевременно. В целом, проблема, освещенная в статье, актуальна, интересна. Действительно, изучение процессов обмена железа у пациентов с РАС может показать их метаболическое и биохимическое разнообразие и в то же время способствовать выявлению метаболически однородных групп для развития персонифицированной медицины.

\section{СПИСОК ЛИТЕРАТУРЫ}

1. autism-aba.blogspot.com [интернет]. Диагностика и лечение аутизма. Американская психиатрическая ассоциация отдала свой голос в поддержку DSM-5 [доступ от 11.08.2018]. [American Psychiatric Association Approves DSM-5 Revisions. (In Russ).] Доступ по ссылке http://autism-aba.blogspot.com/2012/12/ approval-of-dsm-5.html.

2. Deliens G, Leproult R, Schmitz R, et al. Sleep disturbances in autism spectrum disorders. Rev J Autism Dev Disord. 2015;2(4): 343-356. doi: 10.1007/s40489-015-0057-6.

3. Cusenzaa M, Accardoa A, Zaninib S, Brambillab P. Analysis of awake and sleep EEG in autistic children. Int $J$ Bioelectromagn. 2012;14(2):80-83.

4. Строганова Т.А., Орехова Е.В., Галюта И.А. Нейронные механизмы нарушений ориентировки внимания у детей с

\section{ИСТОЧНИК ФИНАНСИРОВАНИЯ}

Не указан.

\section{FINANCING SOURCE}

Not specified.

\section{КОНФЛИКТ ИНТЕРЕСОВ}

Автор статьи подтвердила отсутствие конфликта интересов, о котором необходимо сообщить.

\section{CONFLICT OF INTERESTS}

Not declared.

\section{ORCID} 6851

О. В. Кожевникова http://orcid.org/0000-0001-8562-

расстройством аутистического спектра // Экспериментальная психология. - 2015. - Т. 8. - № 3- С. 7-23. [Stroganova TA, Orekhova EV, Galuta IA. Neural basis of attention orienting abnormalities in children with autism. Experimental Psychology (Russia). 2015;8(3):7-23. (In Russ).] doi: 10.17759/exppsy. 2015080302.

5. Karvat G, Kimchi T. Acetylcholine elevation relieves cognitive rigidity and social deficiency in a mouse model of autism. Neuropsychopharmacology. 2014;39(4):831-840. doi: 10.1038/ npp.2013.274.

6. Shukla A, Agarwal KN, Shukla GS. Latent iron deficiency alters gamma-aminobutyric acid and glutamate metabolism in rat brain. Experientia. 1989;45(4):343-345. doi: 10.1007/ bf01957472.

\section{Из истории медицины}

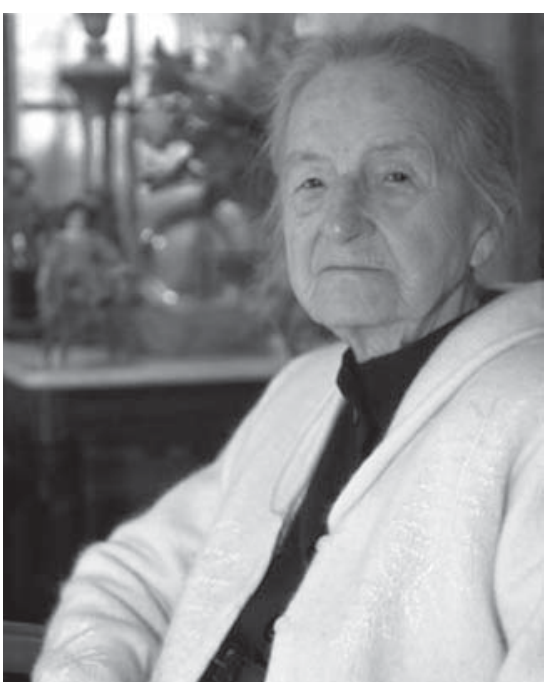

“НИКОГДА НЕ ДЕЛАЙТЕ И НЕ ГОВОРИТЕ ТОГО, О ЧЕМ ОДНАЖДЫ ЗАХОТИТЕ ЗАБЫТЬ..." Лейла Элис Денмарк (1898-2012) американский педиатр, известная не только своим долгожительством.

Лейла Элис получала педагогическое образование, когда ее жених Д.Денмарк был отправлен на о. Ява в Индонезию государственным департаментом Соединенных Штатов, куда не разрешалось брать жен.
Бросив педагогику, ей пришлось поступить в медицинскую школу: она была единственной женщиной среди выпускников Медицинского колледжа Джорджии 1918 г.

К частной практике Денмарк приступила с 1931 г. В 1932 г. занималась эпидемией коклюша, унесшей в Джорджии 75 человеческих жизней. Благодаря ее исследованиям, в ходе которых ей удалось вылечить собственную дочь, было начато производство вакцины против коклюшной палочки.

В возрасте 87 лет Денмарк хотела уйти на пенсию, для чего переехала в тихий городок Альфаретта в северной части штата, но в конечном счете продолжила работать врачом и там. А на пенсию вышла только в 2001-м - из-за проблем со зрением, и в свои 103 года она, вероятно, была старейшим практикующим врачом в мире. Секрет долгой жизни объясняла правильным питанием и тем, что любила все, что делала: “Когда делаешь то, что не любишь - это работа. Когда занимаешься любимым делом - это игра. я не работала ни дня в своей жизни". А главное, советовала не думать о завтрашнем дне: "Стоит ли? Завтра может и не наступить".

Денмарк оказалась одним из первых врачей, указавших на вред курения в присутствии детей. Она резко критиковала прием наркотиков, употребление кофе и алкоголя беременными женщинами
Считала, что употребление коровьего молока не приносит пользы детям: «Когда ребенок перестает сосать мамину грудь ни чая, ни кофе, ни кока-колы. Только вода. От коровьего молока дети становятся анемичными. Теленок, когда перестает сосать вымя, идет на пастбище. Он ест только траву. И каким здоровым, сильным вырастает. Я никогда не пробовала кока-колы, чая или кофе. С 7 месяцев пила только чистую воду". Вместо соков Денмарк рекомендовала есть овощи.

Свою позицию не брать плачущего младенца на руки объясняла так: “Ребенок должен плакать до 8 ч в день. Это часть развития его легких. Позвольте ему плакать, пока он мал. Иначе будете плакать вы, когда он вырастет». При этом Денмарк не утверждала, что ее методы единственно правильные: "Никогда не скажу другому специалисту, что его рецепт ошибочен. Выбор - за родителями. Только они могут знать, что лучше для их ребенка".

В 1971 г. Денмарк опубликовала книгу под названием "Каждый ребенок должен иметь шанс", где изложила свою философию отношения к детям. Считала «единственной стоящей работой на Земле" быть хорошим родителем - матерью или отцом. И в любой ситуации советовала сохранять чувство юмора.

(по материалам сайта ECONET) https://econet.ru/articles/168861-zolotyepravila-zhizni-leyly-elis-denmark 